\title{
DEMOGRAFIA E FAMÍLIA: AS TRANSFORMAÇÕES DA FAMÍLIA NO SÉCULO XXI
}

\author{
DEMOGRAPHIC AND FAMILY: THE TRANSFORMATION OF THE FAMILY ON THE XXI CENTURY
}

DEMOGRAFÍA Y FAMILIA: LA TRANSFORMACIÓN DE LA FAMILIA EN EL SIGLOXXI

\author{
Mônica Cristina da Silva - UFG - Goiânia - Brasil \\ monicgeo@yahoo.com.br \\ Eguimar Felício Chaveiro - UFG - Goiânia - Brasil \\ eguimar@hotmail.com
}

\begin{abstract}
Resumo
0 imaginário brasileiro contemporâneo, ao representar a família, demonstra o seu nível de conflito. Expressões como "a família é a única salvação dos perigos do mundo" ou "a família é a fonte de todas as desgraças atuais", testemunham esse conflito. Junto ao conflito de representação, há, inegavelmente, um fato: a família contemporânea sofre grandes transformações, que atingem a relação de poder entre marido e esposa, o papel do pai e da mãe, a luta pela sobrevivência, a sexualidade, 0 afeto, a existência de novas máquinas de produzir o desejo, o nascimento de diversos tipos familial, a ação da parentalidade, etc. Com o objeto de problematizar essas características e refletir essas mudanças, esse artigo, ao encadear uma leitura demográfica da família, intenta ver a sua densidade histórica de acordo com as mudanças do espaço. Ao final demonstra que a complexificação da família atual - e os seus conflitos - coloca novos desafios à pesquisa do assunto.
\end{abstract}

Palavras-chave: Família contemporânea. Fronteiras da família. Diásporas familiares.

\begin{abstract}
The Brazilian imaginary contemporary, to the represent the family, show his level of conflict. Expressions like "the family is the only salvation of the dangerous of the world" or "the family is the source of all the woes current", witness this conflict. Together of the conflict to representation, there is, undeniable, a fact: the contemporary family suffer big transformations, that affect the power of relationship between husband and wife, the role of the mother and father, the struggle for survival, sexuality, affection, the existence of the news machines to produced the desire, the born of the various types of a family, the action of parenting etc. with the object of exposing this features and reflect the changes, this paper, to repent a demographic reading of the family, intent to see his historic density according to changes on the space. At the end shows that the complexity of the current family - and their conflicts - poses new challenges to research the subject.
\end{abstract}

Key words: Contemporary family. Families frontier. Diasporas family.

\section{Resumén}

La imaginación brasileña contemporánea, al representar la familia, demuestra el nivel de conflicto. Expresiones como "la familia es la única salvación de los peligros del mundo" o "la familia es la fuente de todos los problemas actuales," dan testimonio de este conflicto. Junto a la representación de los conflictos, es innegable un hecho: la familia contemporánea sufre gran cambios, que alcanza a la relación de poder entre marido y mujer, el papel de padre y madre, la lucha por la supervivencia, la sexualidad, el afecto, la existencia de nueva maquinaria para producir el deseo, el nacimiento de familiares de varios tipos, la acción de la crianza de los hijos, etc. Con el objeto de la exposición de estas características y reflejar estos cambios, este artículo, al encadenar uma lectura demográfica 
de la familia, intento para ver la densidade histórica de acuerdo con los câmbios en el espacio. Al final muestra que la complejidad de la familia actual - y sus conflictos - plantea nuevos retos a la investigación del tema.

Palabra-claves: Familia contemporânea. Frontera de la família. Diásporas familiar.

\section{Introdução}

Algumas perguntas. Muitas perguntas. Necessárias perguntas para um começo de reflexão. Quais são as raízes históricas da família nuclear moderna? Como esse assunto foi trabalhado na história da pesquisa demográfica? É possível periodizar a história da família? Quais são os cernes conceituais e as variáveis que podem facultar uma leitura da transformação da família contemporânea? Que contradições povoam o debate atual sobre o fenômeno familiar?

Essas perguntas mobilizarão a presente reflexão, feita com base numa interlocução com vários autores e primada em observações desenvolvidas no cotidiano da vida urbana e, especialmente, por meio de pesquisas realizadas junto a orientandos do curso de geografia.

Os fenômenos demográficos sintetizados no cerne do objeto de estudo dessa área do conhecimento - a construção social do indivíduo humano no espaço e no tempo - se torna uma fonte rica de investigação, embutida de uma complexidade de análises que nos desafia. Portanto, entender a família no contexto de complexidade dos fenômenos e dos processos demográficos atuais, exige, também, a compreensão das transformações sociais que recaem sobre as variáveis que a pensam.

É no contexto das transformações sociais que pode-se interpretar as principais variáveis demográficas do período atual, dentre elas, o tamanho da população, a sua distribuição por sexo, as mudanças dos perfis quantitativos e qualitativos da etariedade, a distribuição da população segundo regiões geográficas, a dinâmica da população, a natalidade, a fecundidade e a mortalidade.

Dentre essas variáveis de interesse interpretativo da Geografia da População se situa o estudo da família e o que, hoje, a compreende, a constrói e nos desafia, como os seus novos desenhos, os papéis diferenciados assumidos pelos seus entes; a relação marital a partir da inclusão da mulher no mercado de trabalho; a mudança na dimensão temporal de convivência; a instabilidade econômica causada pelas mudanças na macroeconomia resvalando no desemprego estrutural; a situação espacial em forma de vida urbana; a diminuição da quantidade de filhos. 
Essas mudanças repercutem em interrogações, como: o que é ser pai e o que é ser mãe no atual contexto? Ou então: os laços consanguíneos dão conta de explicar os níveis de relação entre os sujeitos que definem a célula familiar?

Pai alcoólatras. Mães neuróticas e depressivas. Filhos desobedientes. Tios longínquos. Avós gagás, objetos de pena. Primos que causam vergonha. Conflito entre irmãos. Crise econômica. Separações iminentes - são essas as características centrais da família contemporânea? Além disso, quais são os novos objetos que povoam os lares das famílias brasileiras e que subjetividade adentra os corpos dos entes por meios desses objetos?

A família grita. Fratura-se. Decompõe-se. Recompõe-se. Reinventa-se. Resiste e altera-se...

A concepção clássica de família patriarcal brasileira durante muitos anos foi fundamento da organização da sociedade. Essa concepção passa a ser criticada pela nova abordagem marxista. No século XIX, a família era objeto analítico do denominado planejamento familiar. A visão Neo-Malthusiana considerava, relativamente, que o número populacional interferia no desenvolvimento do país. Sendo assim, o Estado interferia na taxa de fecundidade, com políticas restritivas com o objetivo de controle da natalidade.

A partir dessa concepção, estabelecia-se uma relação da Família com o Estado enquanto agente interventor e controlista da reprodução familiar. Por um longo período essa discussão gerou certos conflitos de posição entre os demógrafos. Aos poucos, baseando-se em leituras que faziam a relação entre família e sociedade, descobriam-se as contradições sociais como conteúdo das contradições familiares, já que os países pobres eram os que tinham maior taxa de fecundidade e os ricos as menores. A partir desses conflitos, surgem críticas à abordagem dos Neo-Malthusianos, feitas pelos marxistas.

Mais que as críticas, a leitura da família ganhava novas compreensões teóricas e metodológicas: como construção histórica e célula social, lugar da geração do trabalho explorado, por um lado. E lugar da reprodução da ideologia burguesa por outro.

Neste contexto, a família passa a ser analisada não mais pela abordagem do planejamento familiar, mas como uma instituição, a maior do mundo. Enquanto instituição-instituinte o seu sentido não refere-se apenas nas relações de consanguinidade, afetivas, mas como relações de poder (lugar do pai, mãe, irmão - posição que ocupam na família); enquanto uma célula produtiva (condição de trabalho, filhos que ajudam nas despesas, contas a pagar); uma unidade cultural (formadora de hábitos e costumes); uma expressão social no tempo e no espaço (a família da idade média, escravista 
não é a mesma de hoje, está relacionada à classe social); uma micro-célula social; e qualitativamente (pais separados, pai que não conhece os filhos, mãe que vive sozinha com filho, modelos de famílias diversas, arranjos familiares, formas alternativas de famílias, etc.).

Esse desdobramento da compreensão da família, aos poucos a coloca como uma unidade demográfica que vem despertando interesse crescente pelos estudos sobre reprodução, educação, trabalho, forma de organização social, poder, cultura etc. Nesta perspectiva vale questionar e responder: o que é família? Quais os modelos de família hoje? Casamento e procriação são relações diferenciadas? Está ocorrendo a desagregação e destruição da família no século XXI? A sociedade impõe um modelo cultural de família? O modelo patriarcal ainda prevalece?

\section{As transformações familiares: formas e conceitos}

A dificuldade de se estabelecer um conceito de família, atualmente, reflete as mutações e as transformações nos modelos e formas de família tradicionalmente incorporadas no imaginário comum. Cabe então averiguar o modo de representar e os componentes que participam da construção de "ser família hoje” de acordo com as características típicas da organização social atual.

Para Durham (1982), as famílias são grupos sociais, estruturados por meio de relações de afinidade, descendência e consanguidade que se constituem como unidades de reprodução humana. A família tem dupla referência: de um lado representa grupos sociais concretos, reconhecidos pelos seus membros e pela sociedade, de outro lado, refere às regras, padrões, ou modelos culturais.

Mas como modelos, as instituições são mutáveis, suas construções são cheias de exceções que na maioria são tão numerosas quanto ao modelo de família vigente. Dentre esses modelos podemos citar alguns: grupo doméstico maior que a família nuclear (membros da família de um dos cônjuges, afilhados, serviçais.); famílias matrifocais (aquelas formadas basicamente por mãe e filho); novos arranjos familiares (formação de outras famílias casais separados).

Esses modelos de famílias contribuem para o problema da definição das formas de famílias vigentes. Mas como esse modelo foi implantado e como surgiu? 
Para entendermos tal modelo cultural e sua representação devemos resgatar no tempo e no espaço a formação da família brasileira, sem deixar de relacionar aos modos de produção e as relações de produção, contextualizando à forma de colonização e exploração econômica implantada no país.

As formas políticas implantadas no processo de colonização produziram violento processo de descaracterização cultural e destruição das formas de sociabilidade que lhes eram próprias. Essas relações contribuíram para a formação da família cativa pela relação de dominação e escravização, como exemplo tem-se a sexualidade dos escravos que não formava unidades reprodutivas.

A Igreja Católica que cumpria uma missão espiritual no processo colonial, funcionou como agente ideológico do Estado, contribuindo para a degradação das formas familiares dos negros e indígenas, e impondo o modelo familiar português, baseado no patriarcalismo católico.

Esse modelo da cultura portuguesa foi implantado nas sociedades de classe dominante, cujos filhos eram legitimados e assegurados de herança e sucessão, que era um modelo relacionado ao estado conjugal. Dessa maneira, a relação entre cultura e economia fazia unir os preceitos religiosos e o cartório de registro civil.

Para as mulheres de demais classes prevalece o concubinato, utilizadas como objetos sexuais, sem vínculos legalmente reconhecidos eximindo o homem da responsabilidade da prole. A escravização das mulheres contribuiu para fortalecer os padrões de dominação masculina. A representação da família tradicional era patriarcal-patrimonialista, gerada para ser grande em função da necessidade de trabalhadores, que reunia pai-mãe-filhosparentes-agregados; com divisão sexual do trabalho na qual a esposa tinha papéis definidos conforme a representação de sua fragilidade para assuntos da razão, do poder e do trabalho. Assim, a sua principal responsabilidade era o autocultivo da submissão com responsabilidade de cuidar da casa e das crianças.

As famílias rurais constituíam uma unidade de produção básica, sustentada pela agricultura de subsistência, com uma prole numerosa enquanto força de trabalho e controle pelo pai. Um outro grave problema para a formação das famílias neste período refere-se às questões de legalizações das uniões, principalmente, para as classes pobres. $\mathrm{O}$ alto custo do procedimento, distanciamento até os cartórios e a posse de documentos, eram problemas centrais. Para Durham (1982, p. 32): 
No Brasil, pode-se dizer que, o Estado agiu no sentido de restringir o acesso às formas legais de família aos setores mais privilegiados da população. De modo geral a constituição da sociedade brasileira: tenta fortalecer o vínculo familiar das classes dominantes e dificultar os das classes pobres. Mas tem em comum a dominação do homem sobre a mulher.

Tal como temos evidenciado, as transformações sociais das famílias brasileiras estão relacionadas às transformações econômicas, políticas, culturais. A revolução industrial, a modernização, a urbanização e, principalmente, as mudanças nas relações de trabalho afetaram a instituição familiar e as formas de regulamentação da procriação, da família na escola, da família no trabalho, enfim, do "ser família".

Essas transformações ocorreram no tempo e no espaço de formas diversas, isso implicou nas várias formas ou modelos de famílias. As várias formas de ocupação no país pelos migrantes, também contribuíram para mudanças na constituição e nos padrões culturais da população trabalhadora. Os migrantes (europeus) utilizaram sua cultura de origem como instrumento de ascensão social e de exploração de oportunidades novas abertas pela expansão econômica. A partir do senso capitalista, coube à família desenvolver uma espécie de minifábrica da riqueza contrapondo-se às famílias de sobrevivência ligada ao trabalho apenas.

O desenvolvimento do capitalismo no Brasil provocou um acelerado processo de urbanização alimentado por correntes intensas de migrações internas, migrações regionais e interregionais. Esse processo migratório proporciona, parcialmente, a fragmentação dos núcleos familiares de origem (dissoluções de vínculos matrimoniais legais ou de uniões consensuais anteriores). Ao mesmo tempo, facultam para os adultos separados de suas famílias de origem, o estabelecimento de novos vínculos conjugais mais ou menos permanentes, mas, necessariamente, consensuais (elevado custo financeiro e complexidade burocrática).

Um intenso processo migratório pode provocar, portanto, o aumento do número de famílias sem pai, como a dispersão da mulher e dos filhos por outras famílias de parentes. Assim, aumenta o número de famílias mais amplas que o simples grupo conjugal, além de ampliar o número de uniões consensuais nas zonas de maiores migrações.

A transformação do mercado de trabalho com a industrialização, não parece ter afetado os padrões tradicionais de divisão sexual do trabalho nas famílias de baixa renda, mas o que decisivamente alterou é o acesso a técnicas de controle de natalidade e a consequente separação da sexualidade e reprodução. 
O desenvolvimento capitalista e da própria sociedade industrial, dessa maneira, afetam, diretamente, o modelo de família, promovendo a contestação das relações de dominação-subordinação entre homem e mulher, o controle da sexualidade feminina e, também, a própria forma do vínculo conjugal. Um conjunto de bandeiras levantadas, especialmente, no século XX, contra machismo, a favor do feminismo, contra o poder fálico, a favor do divórcio e outras que tiveram como pano de fundo atacar a família patriarcal.

Atualmente, o retrato da família é diferente, não mais corresponde a grandes famílias. A imagem que temos hoje é de uma família pequena, formada pelo pai a mãe e dois filhos. A redução do número de filhos veio acompanhada do controle da natalidade, agora estabelecido pela mulher, enquanto uma escolha própria, não como forma de reprodução, mas refletindo a política de emancipação da mulher.

Essa redução de filhos contribui para a formação de famílias pequenas. Com menos filhos, provavelmente, a próxima geração terá menos tios, sobrinhos, primos, reduzindo assim, a parentela e o seu sentido. Convém interpretar que o custo econômico da família nas grandes cidades, o advento dos meios de evitar a concepção, as dificuldades de manter relações estáveis, ao incidirem sobre a taxa de fecundidade, diminuindo o tamanho da família, recria também a sua lógica cultural e a plataforma de seus poderes, por exemplo, na relação entre marido e esposa, pai e filho, filha e mãe, etc.

Percebe-se que todas essas mudanças qualitativas juntamente com o declínio da fecundidade refletem mudanças na estrutura demográfica de forma global. Já nas décadas de 1960 e 1970 surge uma nova perspectiva para a formação da família, centrada não mais apenas na limitação do número de filhos por mulher, por meio da disseminação do uso de métodos contraceptivos, mas como uma abordagem que incorpora saúde e direitos reprodutivos sexuais de forma integrada, de acordo com a co-responsabilidade e igualdade de direitos entre mulheres e homens. Para Caetano (2004, p. 12):

$O$ direito de escolha sobre quantos filhos ter e quando tê-los, assim como o direito de acesso aos meios para a implementação desta escolha, passa a ser, desta forma, um, entre vários, dos componentes necessários para uma vida reprodutiva saudável e segura.

De maneira que hoje a divisão entre os sexos é menos acentuada ou possui outros contornos, fenômeno que marca a ruptura do quadro tradicional de família. Cuidar da casa e das crianças não é mais uma exclusividade 
feminina. Essas funções domésticas passam também a serem exercidas pelo pai, agora mais participativo e atuante no interior do lar.

Estudos recentes revelam outra característica da população que afeta de forma direta os modelos de família. As análises de Berquó e Cavenaghi (2004) revelam uma intensificação do rejuvenescimento da fecundidade no país, em alguns casos como o fenômeno gravidez de adolescentes. Segundo seus dados, há o registro de um aumento na ordem de $25 \%$ da fecundidade entre jovens e adolescentes, com diferenças substanciais segundo as camadas socioeconômicas. O fenômeno da mãe solteira e do pai desertor, ao se colocar como realidade atual e envolver uma série de conflitos, desafia o planejamento demográfico para rumos mais qualitativos, envolvendo quesitos como a construção do afeto, a luta contra a rejeição, a educação para jovens mães etc.

A mobilidade dos membros da família também representa mudanças significativas no modelo familiar. O deslocamento desses membros, seja por trabalho ou estudo, pode proporcionar a formação de outros arranjos familiares e o distanciamento do contato entre os membros da família. A disputa global pelo emprego e a construção igualmente global do desemprego, ao criar um espaço instável gera relações distantes entre os membros consanguíneos.

À medida que isso tem ocorrido com mais frequência e com mais força, por certo, o controle familiar dos pais sobre os filhos enfraquece e junto o desconhecimento das trajetórias dos filhos, resvalando no modo como o afeto é constituído. Observa-se, também, que isso pode criar um distanciamento do mundo simbólico dos pais relativo ao dos filhos.

A família hoje passa por transformações sociais que trazem consigo a insegurança, a incerteza, representando relações conjugais menos estáveis. O casamento nesta relação perde sua estabilidade. Segundo Medina (2002, p. 25), "o casamento passou a ter um papel social menos central e o companheirismo tornou-se corrente e aceito".

Um fato positivo da separação, além da divisão do poder entre homem e mulher, é deslocar a união de um preceito moral para um preceito afetivo. Nasce aqui, no contexto das lutas políticas minoritárias, como é o caso do casamento de sujeitos de mesmo gênero, desenvolver outro fundamento para a família, não baseando-se mais na consanguinidade, mas no afeto.

Por outro lado, as dificuldades de relação entre membros casados, expressam também a intromissão do mundo no seio familiar, desde a aceleração do tempo, a ação de novas máquinas de produção do desejo, e, in- 
clusive, a participação das "novas doenças da alma”, como a ansiedade, os transtornos, a fragmentação identitária, a depressão etc.

Para Moreira (2002), lidar com a família hoje é lidar com a diversidade, que pode ser classificada em várias tipologias, como: famílias intactas (que ainda não sofreram processo de separação); famílias em processo de separação; famílias monoparentais; famílias reconstruídas; famílias constituídas por casais homossexuais; famílias constituídas com filhos adotivos; famílias constituídas por meio de novas técnicas de reprodução.

Estes vários modelos ou relações familiares desencadeiam inúmeras situações, como: ter filhos antes de casar; separação do casal seguida de mudanças dos filhos para a casa de parentes; filho morando com o pai ou com a mãe, este se casa novamente e tem outros filhos; uniões de casais separados com a presença dos filhos do casamento anterior; uniões de casais separados morando cada um com seus filhos em casas separadas. Para Moreira (2002), torna-se difícil a clareza do conceito de família, quando o utilizamos e correlacionamos idealmente "família" com "casal e filhos"; etc.

A realidade nos revela que a família contemporânea se desdobra numa multiplicidade de formas e numa complexidade de relações, principalmente, por considerar que não haveria como o seio familiar não revelar as características culturais da sociedade atual referentes aos costumes, hábitos e contradições sociais. Essas novas formas de "ser família" produzem certos conflitos e até mesmo preconceito para os que não seguem o "modelo" aceitável.

A história da família demonstra que ela sempre passou por múltiplas transições. Sendo assim, a família como instituição, como sistema humano em constante interação, seja afetiva ou consanguínea, revela a perplexidade social por meio de códigos que envolvem também o sentido da paternidade, da maternidade, do corpo, da saúde, etc. Portanto, ao não existir um único tipo de família, um único modelo, as outras instituições como, por exemplo, as religiosas, as políticas ou as de ascendência cultural criam diferentes representações e significados de seu valor, de sua importância e de seus deveres.

\section{0 poder político da família contemporânea: fronteiras e diásporas}

Alguns fatos elucidam a questão. Recentemente, um pai, com lágrimas nos olhos, diante da neurastenia violenta do filho, teve que sacrificálo em nome da proteção de outros entes. Um padrasto estuprou a enteada, 
depois a matou para que ela não o delatasse. A filha adolescente, após longos bate-papos pelo Messenger, fugiu com o namorado internauta e nunca mais voltou para a casa para o desespero da mãe. Um marido goiano migrou para os EUA e casou com uma americana criando uma bigamia alémmar. Uma mãe, no aniversário de um ano de seu filho, numa casa de show, começou a cerimônia mostrando um filme de seu filho desde a primeira ultrassonografia.

Estes fatos reais nomeiam problemas e situações sociais do nosso tempo, como a violência urbana; doenças como pedofilia e depressão; intervenção das novas tecnologias na formação da subjetividade; reestruturação de laços afetivos; espetacularização e narcisismo de classe, etc.

Além desses fatos demarcados em páginas policiais ou assumindo as principais pautas de jornais de TV, um conjunto de representações direcionado à família brasileira contemporânea pode apresentar sinais do modo como ela é vista. Expressões como "a família é a raiz de todas as desgraças atuais”, "a violência é produto da crise da família”; "não se faz pais como antigamente, os de hoje deixam os filhos fazerem o que querem”, "a família foi a instituição tradicional mais sacrificada diante das mudanças contemporâneas", "olhe o que ocorre dentro de uma casa e veja a desgraça do mundo", "aquele sujeito é bom, ele é de família”, "a família é problemática, mas sem ela é pior", "na hora "H recorremos à família".

As representações se multiplicam e mostram, não apenas o modo como a família é vista, mas como é ideologizada. É por isso que vários candidatos a cargos eletivos saem de mãos dadas com esposa e filhos em períodos de pleitos eleitorais; ou setores de vários tipos de religião colocam em sua pauta a defesa da família.

No campo da ação prática, projetos endereçados para a agricultura familiar, ou programas de saúde e família, princípios da economia doméstica, campos de saberes como as constelações familiares ou metodologias ligadas à terapia familiar evidenciam que as organizações familiares estão no núcleo de atividades de controle, de formação da ideologia, de organização do trabalho e também de efetivação do consumo, do lazer, etc.

Descortinar o sentido político da família desdobra em quesitos de profunda particularidade: que tipo de formação moral o pai deseja ao filho? Como a mãe ajuda criar o filho para o consumismo? Como um pai pode ser uma referência humana imerso no alcoolismo, por exemplo?

Na família se perpetua preconceitos, cria estilos de condutas, de falar e de relacionar com o outro. O seu valor político também mostra a impor- 
tância do afeto como consistência para que entes enfrentem os problemas do mundo. Mas isso tudo, numa lógica em que a família, em estado de diáspora, vê abrir, em seu seio, novas fronteiras.

Desde os símbolos estranhos às raízes culturais dos pais, que povoam o lar pela via dos novos objetos técnicos, como internet, mídia, etc, incluindo a necessidade de a mãe ter que acumular funções dentro e fora da casa; o tempo fragmentado do pai e da necessidade de os filhos saírem cedo do lar em nome da formação intelectual ou do trabalho em lugares diferenciados de seus pais, o que se desenha é uma diáspora dos entes da família recriando fronteiras entre si.

Essas fronteiras distanciam um membro do outro, recolocam os componentes da tradição no lume da sociedade contemporânea - e de suas contradições. Se antes havia um afeto respaldado na coerção de valores e na confiança, agora, o estremecimento da confiança pode fazer par com outro dispositivo afetivo, por exemplo de, filhos e pais livres da coerção, deslocar seus afetos para as madastras, para os padastros ou para entes adotivos.

\section{Considerações finais}

O Brasil pela forma de colonização recebida sofreu a imposição de um único modelo de família, centrado na relação conjugal patriarcalista. O sistema de dominação da sociedade brasileira tradicional não impediu a emergência de modelos alternativos, o que significou uma diferenciação dos grupos familiares além do controle de reprodução, dando origem a arranjos domésticos distintos.

A transformação da sociedade associada à emergência do trabalho livre e ao desenvolvimento do capitalismo industrial promoveu a ampliação do número de famílias estáveis e legalmente constituídas entre as classes trabalhadoras. Por outro lado, provocou, ao longo do tempo, um enfraquecimento das relações de parentesco, isolando o grupo conjugal da parentela, ao mesmo tempo em que restringia - sem eliminar - a dominação paterna.

O retrato da família hoje representa as mudanças nas formas concretas dos papéis de membros familiares como também no modelo cultural; na circulação simbólica, nas relações sociais da sociedade, na propagação de novos ingredientes tecnológicos e em novas bandeiras políticas.

Observa-se também que as mudanças sociais de um período histórico em que as diferentes sociedades recriam a divisão internacional do traba- 
lho, mudando a forma e o conteúdo do trabalho, as disputas por mercado, etc, a sociabilidade baseada no consumo, como é a sociedade global, influencia o conteúdo da família.

Convém averiguar que os problemas estruturais dessa mesma sociedade, como o desemprego global ou estrutural, as desigualdades sociais, a fome ou os advindos da concentração da população nas cidades, criam diásporas e fronteiras entre as famílias.

No entorno dessas mudanças e em suas implicações ocorrem verdadeiros processos de desmapeamentos de sentido de família a par da produção de novos desejos. O indivíduo arraigado ao mundo liberal, com forte pendor narcísico, hedonista, ao mesmo tempo que vive rogando afetos mais consistentes, não suporta as negociações geralmente neuróticas do cotidiano familiar.

Nasce, então, um nível grande de separação como, noutra vertente, recria-se estímulos para relações duráveis que sejam capazes de ressarcirem a demanda de afeto. Pode ser que, fora do âmbito familiar, o desejo de comunidade (Pelbart, 2003) procura outras direções. Está posto que o afeto saudável e os sentidos de vida podem se darem fora do casamento, da família nuclear ou de laços civis normativos. Como há a advertência que não foi inventado outro grupo, que não a família, que pudesse dar acolhida à aquelas demandas.

O fato é que a complexificação da família estimula novas pesquisas demográficas, apresentando outras temáticas que, por sua vez, exigem novas metodologias.

\section{Referências}

BARTHOLO, Maria Helena. Sobre Filhos e Alunos. Família: O ausente presente dentro da instituição escolar. In: Boletim - PGM 5 - O Salto para o Futuro Parceria Escola e Família. 2002.

BERQUÓ, ELZA; CAVENAGHI, S. Mapeamento socioeconômico e demográfico dos regimes de fecundidade no Brasil e sua variação entre 1991 e 200. In: Anais do Encontro Nacional de Estudos Populacionais, 14., 2004, Caxambu. Campinas: ABEP, 2004.

CAETANO, André Junqueira. O declínio da fecundidade e suas implicações: uma introdução. Revista Brasileira de Estudos de População. São Paulo, v.21/2, 2004.

DURHAM, Eunice Ribeiro. Família e Casamento. In: Anais do III Encontro Nacional de Estudos Populacionais. Vitória: ABEP. v. 1, p. 31-50, 1982.

MEDINA. Carlos Alberto de. Escola: um espaço em transformação. In: Boletim - PGM 5 - 0 Salto para o Futuro Parceria Escola e Família. Maio, 2002. 
MOREIRA, Berenice Fialho. Nova Família, Nova Escola? O que há de novo nas novas famílias? In: Boletim - PGM 5 o Salto para o Futuro Parceria Escola e Família. Maio, 2002.

PELBART, P. P. A vertigem por um fio: Políticas da subjetividade contemporânea. São Paulo: Iluminuras, 2000.

Vida Capital: ensaios de Biopolítica. São Paulo: Iluminuras, 2003.

ROLNIK, S. Cartografia Sentimental: transformações contemporâneas do desejo. São Paulo: Estação Liberdade, 1989.

SANTOS, Milton. Espaço e Método. São Paulo: Nobel, 1985.

. SILVEIRA, Maria L. O Brasil: Território e sociedade no início do século XXI. Rio de Janeiro: Record, 2001.

Mônica Cristina da Silva - Mestre em Geografia pelo Programa de Pós-graduação do Instituto de Estudos Sócio-ambientais da UFG.

Eguimar Felício Chaveiro - Professor titular do Instituto de Estudos Sócio-ambientais da UFG.

Recebido para publicação em Setembro de 2009

Aceito para publicação em Dezembro de 2009 